Check for updates

Cite this: RSC Adv., 2017, 7, 55232

Received 12th October 2017

Accepted 18th November 2017

DOI: 10.1039/c7ra11271h

rsc.li/rsc-advances

\section{Research on influencing factors and its optimization of metal powder injection molding without mold via an innovative 3D printing method}

\begin{abstract}
Xiaokang Yan, Liang Hao, (iD * Wei Xiong and Danna Tang
Using laboratory-made three-dimensional (3D) printing equipment, an innovative 3D printing process without a mold, which was based on metal powder injection molding (MIM), was developed for the fabrication of complex 3D metal and alloy components. Copper powder and paraffin wax were selected for the composition of the copper paste composite. The study was performed to analyse the effects of printing process parameters on the layer-by-layer injection and forming mechanism of the copper paste. Furthermore, the effects of heating parameters during the sintering process on the microstructure and some physical properties of the samples were investigated. The results revealed that the sintering temperature of the copper paste was initiated at a lower temperature (ca. $300{ }^{\circ} \mathrm{C}$ ) than that of bulk copper metal. The optimal conditions of the heating process of copper paste were explored. The optimal conditions of the sintering temperature were above $950{ }^{\circ} \mathrm{C}$ with a holding time of $120 \mathrm{~min}$. Herein, a metal component was manufactured with a complex 3D structure, dense microstructure, superior metallurgical bonding and a flat surface based on our research. The results of our study demonstrate the potential to manufacture metal and alloy components by means of a low cost 3D printing technique.
\end{abstract}

\section{Introduction}

Advanced equipment, unmanned aerial vehicles and artificial satellites, and other high-tech areas following the low energy consumption and miniaturization trend have made small components and structures of $10 \mu \mathrm{m}$ to $100 \mathrm{~mm}$ have a huge market demand. Processing and forming methods based on micro-components have become hot topics. ${ }^{1,2}$ Metal materials with excellent mechanical properties and processing performance in the field of micro-metal and alloy parts manufacturing have attracted the attention of researchers around the world. Metal powder injection molding (MIM), an established net-shape manufacturing process that combines powder metallurgy with plastic injection molding, is an effective method for manufacturing metal and alloy components. ${ }^{3-5}$ It capitalizes on the most useful characteristics of powder metallurgy (e.g. low-cost, simplicity, flexibility of composition selection and inexpensive raw materials) and plastic injection molding (e.g. ability to manufacture complex parts and rapid production) to manufacture small-to-medium sized intricate components. ${ }^{6}$ However, despite the advantages of MIM in the mass production of metals and alloy components, it is not conducive to the personalized manufacturing of components

Advanced Manufacturing Research Center for Jewelry, Gemological Institute, China University of Geosciences, Wuhan, 430074, China. E-mail: haoliang4883@outlook. com; Fax: +86 27 87482950; Tel: +862767884883 due to it requiring the use of a mold before manufacturing. In addition, the design and use of molds make it difficult for MIM to realize the fabrication of micro-metal parts with complex three-dimensional (3D) structures. Therefore, in order to solve these problems, in this work an innovative 3D printing process without a mold and based on MIM was used for the fabrication of complex 3D metal and alloy components via a copper paste injection printing process and laboratory-made 3D printing equipment.

$3 \mathrm{D}$ printing is an additive manufacturing technology, exhibiting the ability to manufacture metallic components with complex structures and advanced functionality. ${ }^{1,7} \mathrm{~A}$ variety of 3D printing methods such as Laser Micro Sintering (LMS), Selective Laser Melting (SLM) and Electron Beam Melting (EBM) have been applied to produce 3D metallic structures. ${ }^{8-10}$ In this work, an innovative 3D printing technique via metal paste injection 3D printing based on MIM was developed for the fabrication of complex 3D metals and alloys. Metal paste injection 3D printing uses the material deposition principle to form 3D shapes layer-by-layer, similar to Fused Deposition Modeling (FDM), ${ }^{11,12}$ but it requires a sintering process to remove the adhesive material and consolidate the metallic materials. A specific binder wax material is mixed with fine metal particles to formulate paste composites. These metal pastes can be heated to semi-molten pastes and injected from a fine deposition nozzle. Then the injected material is cooled and solidified layer-by-layer to form $3 \mathrm{D}$ shapes. Then the $3 \mathrm{D}$ 
solidified paste part is heated up in the oven to vaporize the binder materials and the remaining metal powders are sintered into a dense metal part, similar to the post-processing used in the MIM process., ${ }^{3,13,14}$ As using a mold is not required, metal paste injection 3D printing shows a clear advantage over MIM in terms of complex micro-metallic structure fabrication.

Paste injection 3D printing equipment is cost-effective compared to SLM, LMS and EBM equipment, which can also be utilized to print a wide range of materials. However, the main difference between metal paste injection 3D printing and MIM is whether molds are used or not. As a new and emerging technology, it requires further research on basic scientific problems such as the metal paste composition and formulation, interfacial bonding, the dewaxing process and the metal sintering mechanism. In addition, the forming performance control and optimization mechanisms remain to be studied. A recent study reported that $\mathrm{N}$. Kiml et al. used a 3D printer with an extrusion device to deposit a copper powder and polymer paste with high viscosity. ${ }^{\mathbf{1 5 , 1 6}}$ The formed prototype billet could be sintered and post-processed into a $3 \mathrm{D}$ metallic structure in their work. Thus, the feasibility of the moldless mold-ability of MIM technology has been initially confirmed, but they did not establish a link between metal paste injection 3D printing and MIM in theory and technically. Besides, there was no systematic discussion of the factors affecting the forming process and the manufactured metal parts had a very large optimization space due to not only the complexity of the 3D structure but also the micro-structure. Therefore, in order to produce metal and alloy components with more complex structures and excellent physical and chemical properties, the main influencing factors of metal paste injection 3D printing must be analyzed and optimized.

In this work, copper particles were utilized to formulate a paste with a paraffin wax adhesive and the composition ratio of the copper paste was briefly discussed. Using laboratorybased metal paste injection 3D printing equipment, preliminary systematic studies on the regularity and mechanism of the forming control and sintering process were carried out.

\section{Experiment}

\subsection{Materials and experimental method}

For the paste material formulation, copper powders with an average particle size of $0.5 \mu \mathrm{m}$ were selected (the purity was $>99.5 \%$ ), the scanning electron microscopy (SEM) image of which is shown in Fig. 1a. It can be seen that the copper powders are spherical and uneven in size so that small particles can be filled into the gaps formed by the accumulation of large particles, increasing the content of the powder, reducing the paste shrinkage volume and improving the density and mechanical properties of the samples after sintering. ${ }^{\mathbf{1 7}, \mathbf{1 8}}$ Paraffin wax was utilized as a bonding material (density of $0.9 \mathrm{~g} \mathrm{~cm}{ }^{-3}, \mathrm{C}_{n} \mathrm{H}_{2 n+2}(20<n<24)$, and a decomposition temperature of $\left.164.3-315.1^{\circ} \mathrm{C}\right)$.

In order to simplify the analysis, it was assumed that the size of all of the copper powder particles was $0.5 \mu \mathrm{m}$ based on the copper particle size frequency histogram (Fig. 1b) which revealed that $70 \%$ of the copper particle size distribution was in the range of $0.4-0.6 \mu \mathrm{m}$. The paraffin wax was completely immersed in the powder-forming void (regardless of the interface wetting), so that the mass ratio of powder to paraffin $\left(m_{1}: m_{2}=10: 1\right)$ was calculated from an idealized model (Fig. 1b), providing a reference for the preparation of the copper paste.

Laboratory-based paste injection 3D printing equipment was built for experimental study, and is shown in Fig. 2. The equipment is composed of a 3D movement platform (Fig. 2a) and a syringe with a nozzle aperture of $0.3 \mathrm{~mm}$ in diameter (Fig. 2b). The paste was prepared by mixing two materials with a preparation device (Fig. 2c) that agitated and heated up the mixed paste within a temperature range of $50-250{ }^{\circ} \mathrm{C}$. The $3 \mathrm{D}$ movement platform was controlled by $3 \mathrm{D}$ printing slicing software (Cura 2.1.3). Since the copper powder easily agglomerates, it was sieved using a sieve before the preparation of the copper paste to prevent the plugging phenomenon occurring during the printing process. After the preparation of the copper paste was completed, the syringe was shaken to remove bubbles that might have been present in the paste.

The forming of the component is closely related to the printing parameters. In this study, the main factors affecting the formation that were controlled by Cura 2.1.3 include the extrusion amount (controlled by the drive gear diameter), the single layer height and the retraction distance. The parameters of the single variable method were used to observe the bonding between the layers and the surface quality under different printing conditions, so as to determine the best printing parameters.

After the printing process, because the surface energy of the small copper powder particles was high and they were easily oxidised, the use of carbon powder could provide a reducing
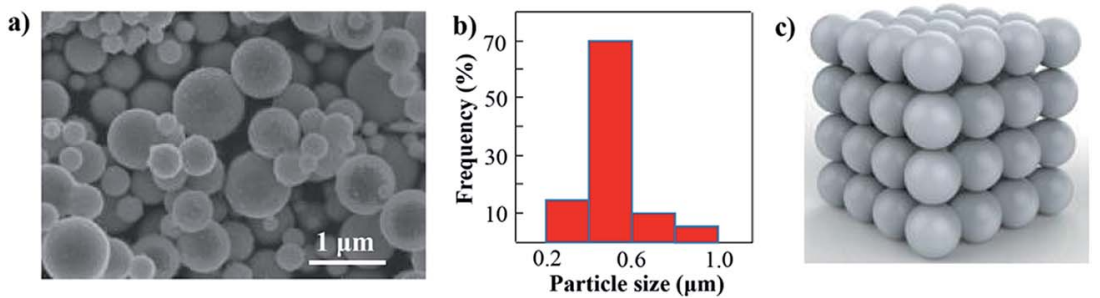

Fig. 1 An SEM image of copper powder and an ideal model of paraffin: (a) an SEM image of copper powder; (b) a copper particle size frequency histogram; (c) an ideal model of the paste system (the gray spheres represent the copper particles). 


\section{a)}

b)

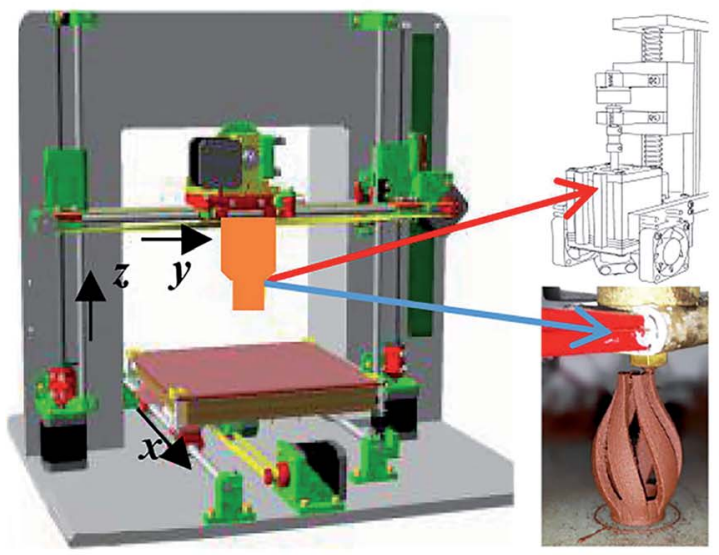

c)

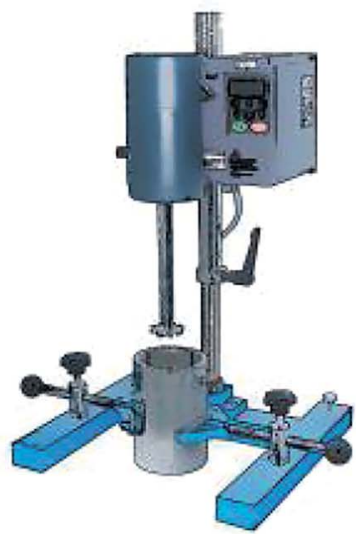

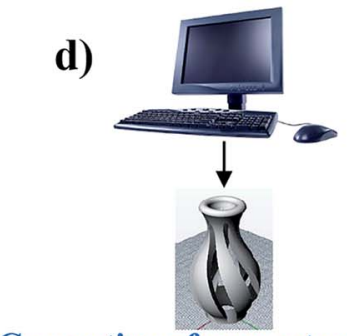

Generation of computer code
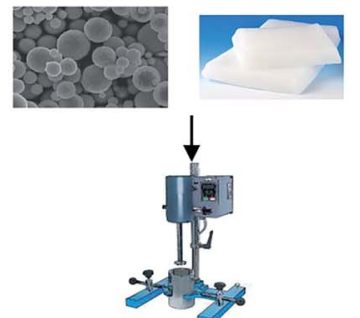

Preparation of copper paste

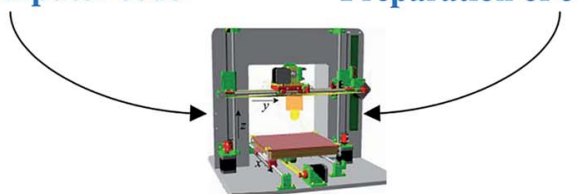

3D printer

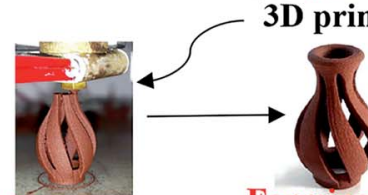

Sintering

Forming parts

Sintered parts

Fig. 2 The 3D printing experiment device: (a) a 3D movement platform; (b) a syringe with a nozzle; (c) a metal paste preparation device; (d) the experimental method and process.

environment in the air atmosphere, and so the deposited copper paste samples were put into a muffle furnace (SX2-5-12, China) under the conditions of carbon powder embedding to explore the sintering process. Besides, due to the capillary force, the carbon powder could improve the liquid mass transfer efficiency of pre-sintering. The microstructure of the samples was observed by a field emission scanning electron microscope (FE-SEM, SU8010, Hitachi, Japan). In order to determine the optimum sintering temperature and holding time, the sample density, hardness, shrinkage and mass sintering loss rate were also measured. The density was measured by a drainage method and the hardness was tested by a digital microhardness tester (HVS-1000B). Before the sintering process, thermogravimetric analysis-differential thermal analysis (TGDTA, STA449F3, Germany) of the copper paste was carried out under a $\mathrm{N}_{2}$ atmosphere with an experimental range of 20$1050{ }^{\circ} \mathrm{C}$ and at a heating rate of $5^{\circ} \mathrm{C} \mathrm{min}^{-1}$. All of the above processes are summarized in Fig. $2 \mathrm{~d}$.

\section{Results and discussion}

\subsection{The effect of printing parameters on the forming quality}

The printing parameters are critical to the manufacturing of the components. Under the conditions of the existing equipment, the complex structures of the 3D components can only be formed under the optimal printing parameters. In this work, in order to obtain the best forming process parameters, the influence of parameters such as the single layer height, retraction distance and extrusion amount on the forming quality and the mechanism was analyzed.

3.1.1 The effect of the single layer height. The single layer height parameter refers to the height of the syringe with the nozzle raised along the $z$ axis when printing the next layer. Fig. 3 shows samples printed at different single layer heights. It can be seen that when the layer height was $0.35 \mathrm{~mm}$, the print quality was poor (Fig. 3a). This is due to the low level of the single layer height in the printing process as the nozzle was too close to the 
a)

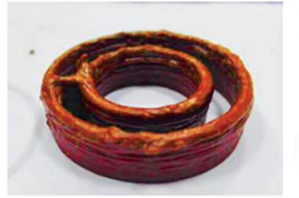

d)

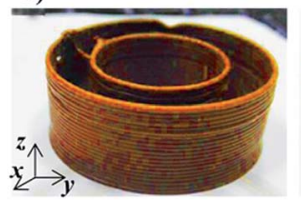

b)

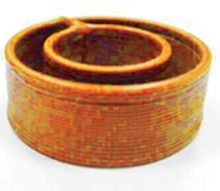

e)

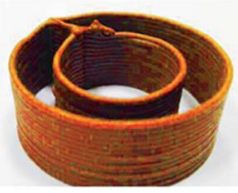

c)

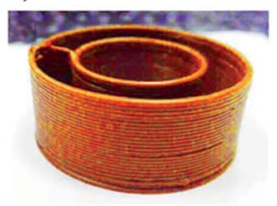

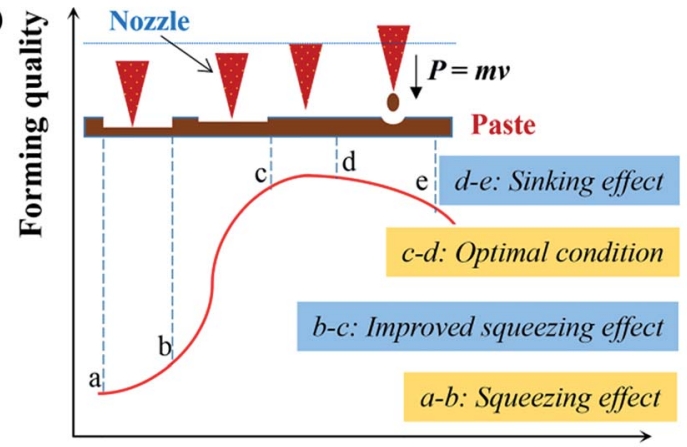

Layer height

Fig. 3 The effect of the single layer height at: (a) $0.35 \mathrm{~mm}$, (b) 0.45 $\mathrm{mm}$, (c) $0.55 \mathrm{~mm}$, (d) $0.65 \mathrm{~mm}$, and (e) $0.75 \mathrm{~mm}$, and (f) the mechanism of the influence of the single layer height on the forming quality.

copper paste below. Thus, the nozzle was buried in the paste, resulting in a "squeeze effect" between the layers. With an increase in the single layer height, the "squeezing effect" was improved, leading to better printing quality and more flat surface between layers (Fig. 3b). When the layer height was 0.55 $\mathrm{mm}$, the best forming quality was obtained (Fig. 3c), and with the increase in the number of print layers, the forming process maintained good stability. By further increasing the layer height, the high gravitational potential energy of the injected paste was transformed into kinetic energy when injecting the next layer, so the deposited paste gave an impulse to the previous layer, causing a "sinking effect". The accumulation of the sinking effect made the nozzle gradually move away from the previous layer, resulting in worse forming quality (Fig. 3d and e).

Based on the above analysis, the influence mechanism of the single layer height on the forming quality can be summarized as the following four stages (Fig. 3f). When the layer height is too small, because of the "squeeze effect", the forming quality is poor, corresponding to section a-b in Fig. 3f. With an increase in the single layer height, the forming quality is improved due to the improvement of the "squeeze effect" (section b-c in Fig. 3f) until the best forming effect is obtained (section c-d in Fig. 3f). By further increasing the layer height, the impulse effect of the deposited paste causes a "sinking effect", leading to worse forming quality again, corresponding to section d-e in Fig. 3f. Obviously, the corresponding single layer height of section c$\mathrm{d}$ in Fig. 3f is optimal.
3.1.2 The effect of the retraction distance. The retraction distance parameter refers to the height of the extruded screw raised along the $z$ axis when printing the next layer. The effect on the forming of the sample under different retraction distances is illustrated in Fig. 4. When the retraction distance parameter was set to $0.5 \mathrm{~mm}$, it can be seen that there was an obvious bulge at the $x-y$ two-dimensional (2D) plane interface (Fig. 4a). This is because the retraction distance was small, and the paste attached to the nozzle was not withdrawn, so the interface was repeatedly deposited with copper paste during the printing process of the next layer, leading to the convex phenomenon. With an increase in the retraction distance, the bulge at the interface became smaller and gradually disappeared (Fig. $4 \mathrm{~b}-\mathrm{e}$ ). When the retraction distance was set to $1.7 \mathrm{~mm}$, the forming effect was the best (Fig. 4f), and on further increasing the recovery value a gap then appeared in the forming sample in the $x-y$ 2D plane (Fig. $4 \mathrm{~g}$ ), which was mainly caused by the retraction distance being too large. Because the copper paste had not yet been extruded but the nozzle began to move according to the preset procedure, a gap was formed (Fig. $4 \mathrm{~g}$ and $\mathrm{h}$ ). The mechanism of the influence of the retraction distance on the forming quality can be summarized as illustrated in Fig. 4 i. a)

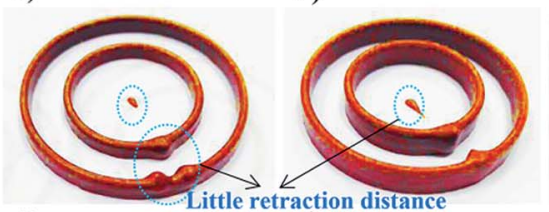

d)

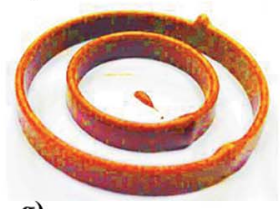

g)

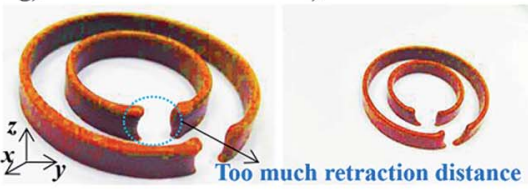

c)

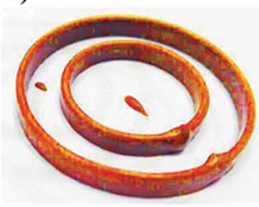

e)

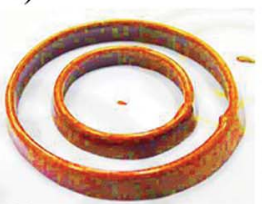

f)

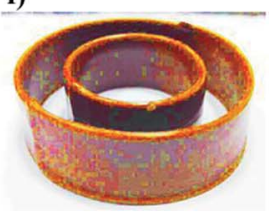

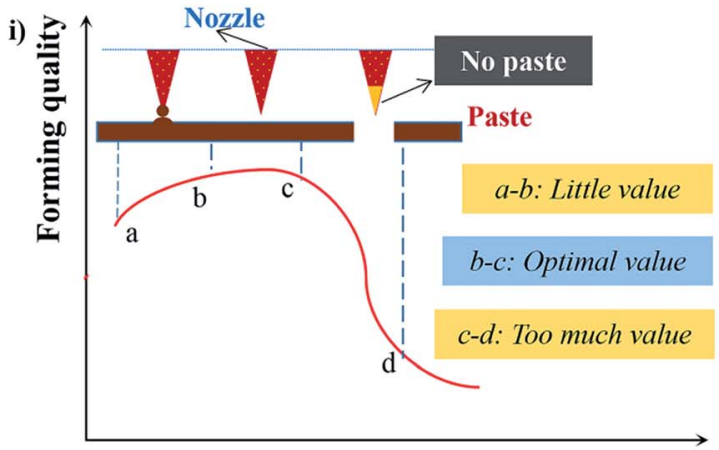

Retraction distance

Fig. 4 The effect of the retraction distance at: (a) $0.5 \mathrm{~mm}$, (b) $0.7 \mathrm{~mm}$, (c) $1.0 \mathrm{~mm}$, (d) $1.2 \mathrm{~mm}$, (e) $1.5 \mathrm{~mm}$, (f) $1.7 \mathrm{~mm}$, (g) $2.0 \mathrm{~mm}$ and (h) 2.4 $\mathrm{mm}$, and (i) the mechanism of the influence of the retraction distance on the forming quality. 
3.1.3 The effect of the extrusion amount. The extrusion amount can be understood as the mass or volume of paste deposited from the nozzle at a length of one unit injected by the screw, which can be controlled by the drive gear diameter of the $3 \mathrm{D}$ printer through a software program. The drive gear diameter and extrusion amount are negatively correlated, so the drive gear diameter could be selected to explore the effect on the forming quality.

The mechanism of the effect of the drive gear diameter on the forming process is relatively simple compared with that of the line withdrawal value and the single layer height. Samples printed under different conditions of the drive gear diameter are shown in Fig. 5. When the drive gear diameter parameter was at a low level, too much copper paste was injected in the unit time, causing the problem that the sample formed was irregular and paste-like and could not be formed as a $3 \mathrm{D}$ shape (Fig. 5a). With an increase in the drive gear diameter parameter, the forming quality was gradually improved (Fig. 5b and c). When the drive gear diameter was set to $7.5 \mathrm{~mm}$, the forming quality was better and the surface was smooth and uniform (Fig. 5d). Further increasing the drive gear diameter parameter caused the forming quality to deteriorate because of the toosmall extrusion amount resulting in a gap (Fig. 5e and f).

3.1.4 Optimization of the printing parameters. Based on the experimental results above, the law and mechanism of the metal paste 3D injection printing process can be summarized, which could guide the manufacturing of 3D shapes theoretically and technically. According to the research on the printing parameters, the drive gear diameter was set to $7.5 \mathrm{~mm}$, the retraction distance parameter was set to $1.7 \mathrm{~mm}$ and the layer height was set to $0.55 \mathrm{~mm}$, then a complex 3D vase (Fig. 6a) was fabricated via the printing process (Fig. 6b) based on a computer model (Fig. 6c). It can be seen that the 3D vase had a complex 3D structure with a fine surface flatness without any post-processing.

\subsection{Thermodynamic properties of copper paste}

After the forming parts are obtained, the sintering process must be carried out to complete the manufacturing of the a)

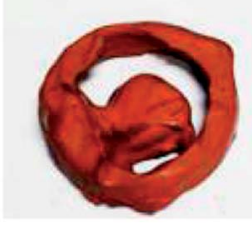

d)

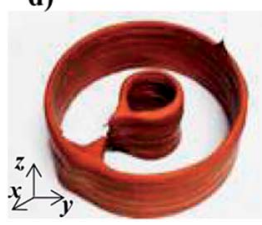

b)

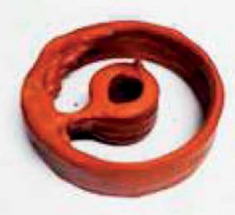

e)

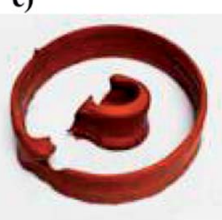

c)

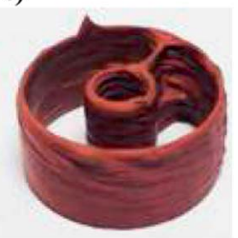

f)

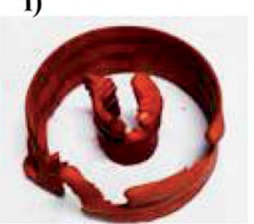

Fig. 5 The effect of the drive gear diameter parameter (extrusion amount) at: (a) $4.0 \mathrm{~mm}$, (b) $5.5 \mathrm{~mm}$, (c) $6.5 \mathrm{~mm}$, (d) $7.5 \mathrm{~mm}$, (e) $8.5 \mathrm{~mm}$ and (f) $9.5 \mathrm{~mm}$.
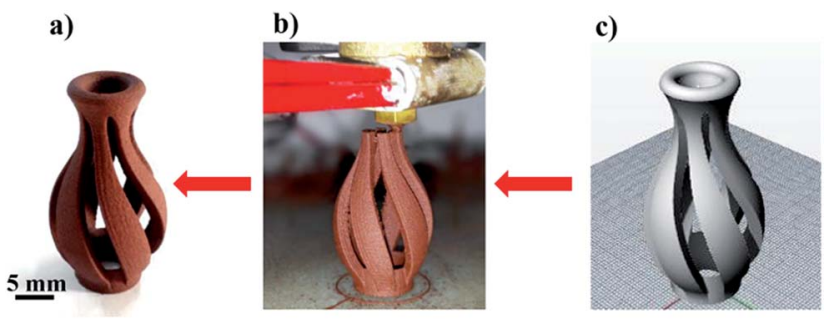

Fig. 6 Optimization of the printing parameters: (a) 3D vase; (b) 3D printing process; (c) computer model.

metal components. The sintering of copper paste is a complicated process, which can be typically divided into two stages: removal of the wax binder and densification of the metal powders. These two stages may not be separated in the sintering process. Prior to the sintering process, the control of the sintering parameters can be guided by thermogravimetric analysis.

The TG-DTA curve is shown in Fig. 7. The TG curve shows that the sample exhibited slight weight loss (less than $2 \%$ ) at $200{ }^{\circ} \mathrm{C}$, indicating that the wax existing on the paste surface started to melt and removal of the wax was initiated. When the temperature increased from 200 to $300{ }^{\circ} \mathrm{C}$, the sample demonstrated severe weight loss (about 10\%), implying that the main stage of paraffin decomposition and removal occurred in this heat phase. As the temperature increased from 300 to $400{ }^{\circ} \mathrm{C}$, the sample exhibited slight weight loss, indicating the end of paraffin decomposition. Beyond $400{ }^{\circ} \mathrm{C}$, the sample quality was almost unchanged. The endothermic peak of the DTA curve at $300{ }^{\circ} \mathrm{C}$ shows that the sintering process of the copper paste was initiated at a lower temperature. The endothermic peak at $900{ }^{\circ} \mathrm{C}$ indicates that the sintering was into the late stage, with the diffusion of atoms and fabrication of grain boundaries occurring at this time.

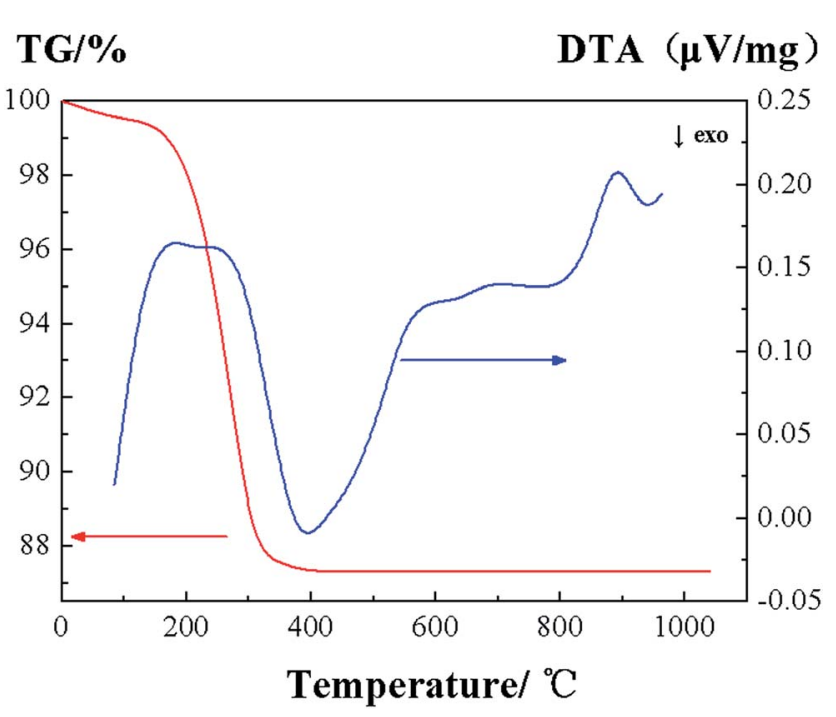

Fig. 7 The TG-DTA curve of the copper paste. 


\subsection{Heating parameters and physical properties}

Sintering is very important and the last step in the metal paste injection 3D printing process, affecting the final physical properties of the samples. From the macroscopic point of view, the external performance of the sintering process is the shrinkage of the product shape; from the microscopic point of view, the sintering process will be accompanied by the removal of paraffin and copper powder densification. Compared with MIM technology, since pressure and a mold were not applied during the metal paste injection $3 \mathrm{D}$ printing process, the content of the metal powder is relatively low and the mechanical properties are poor. Therefore, the sintering process must be strictly controlled. If the sintering process is appropriate, the final parts of the organization can achieve metallurgical bonding, thus creating superior physical properties of the metal components. In this work, the factors affecting the sintering process and its optimization method were analyzed.

3.3.1 The effect of sintering temperature. At different temperatures, the atomic motion within the copper particles and the diffusion ability between the particles are different, affecting the final quality of the sintered parts. The sintering temperature of this experiment was based on the inherent physical properties of pure copper (melting point of $1083^{\circ} \mathrm{C}$ ) and the endothermic peak corresponding to $900{ }^{\circ} \mathrm{C}$ in the thermogravimetric analysis curve (Fig. 7). Therefore, the heat treatment temperature was set at $750{ }^{\circ} \mathrm{C}, 800{ }^{\circ} \mathrm{C}, 850{ }^{\circ} \mathrm{C}, 900{ }^{\circ} \mathrm{C}$, $950{ }^{\circ} \mathrm{C}, 1000{ }^{\circ} \mathrm{C}$ and $1050{ }^{\circ} \mathrm{C}$, while the holding time was set to $30 \mathrm{~min}$ and the heating rate was $10^{\circ} \mathrm{C} \mathrm{min}^{-1}$.

The hardness and densities of the printed samples at different heat treatment temperatures are illustrated in Fig. 8a. The density of the sample showed a slight increase with an increase in the temperature, but it became stable after $900{ }^{\circ} \mathrm{C}$, and the maximum density was $8.1 \mathrm{~g} \mathrm{~cm}^{-3}$ at $950{ }^{\circ} \mathrm{C}$. The hardness of the sample was basically maintained at about $60 \mathrm{HV}$ below $1000{ }^{\circ} \mathrm{C}$, which is significantly higher than that of pure copper casting, and when the temperature reached $1050{ }^{\circ} \mathrm{C}$, which is close to the melting point of copper, the hardness of the sample decreased sharply, equivalent to ordinary castings. The curve of the line shrinkage and mass sintering loss rate of the sample with temperature is shown in Fig. 8 b. It can be seen that the line shrinkage increased as the temperature rose, the main reason for which is that the sintering neck between the particles grew and the pores were excluded with the increase in the temperature, leading to macro-size shrinkage. The mass sintering loss rate also rose with increasing temperature, but the change was not great, since a sintering temperature above $800{ }^{\circ} \mathrm{C}$ was sufficient to break down the paraffin components of the copper paste.

In order to further explore the effect of temperature on the properties of the sintered components, the microstructures of the samples at different sintering temperatures were characterized by SEM, and are shown in Fig. 9. It is shown that the copper particles were sintered together in an interconnected state at $800{ }^{\circ} \mathrm{C}$ and many irregular small grains can be seen, but many pores remained in the sample (Fig. 9a and b). As the atomic diffusion increased with an increase in the temperature, the separated microstructures were gradually sintered together and the pores were excluded (Fig. 9c and d), while the original small pieces of grain formed a large crystal (Fig. 9e). When the temperature reached $1050{ }^{\circ} \mathrm{C}$, the pores were all excluded, and the parts of the microstructure were completely connected together, achieving superior metallurgical bonding (Fig. 9f). The relationship between the hardness, the line shrinkage and the temperature change (Fig. 8a) was also verified by the a)

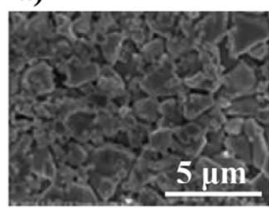

d)

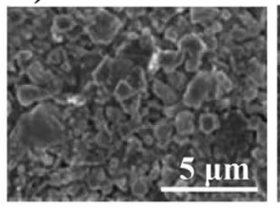

b)

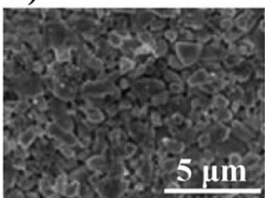

e)

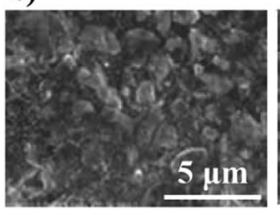

c)

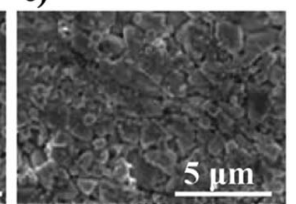

f)

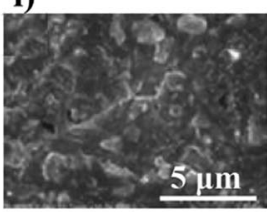

Fig. 9 SEM images of samples at different sintering temperatures: (a) $800{ }^{\circ} \mathrm{C}$; (b) $850^{\circ} \mathrm{C}$; (c) $900^{\circ} \mathrm{C}$; (d) $950{ }^{\circ} \mathrm{C}$; (e) $1000^{\circ} \mathrm{C}$; (f) $1050{ }^{\circ} \mathrm{C}$.
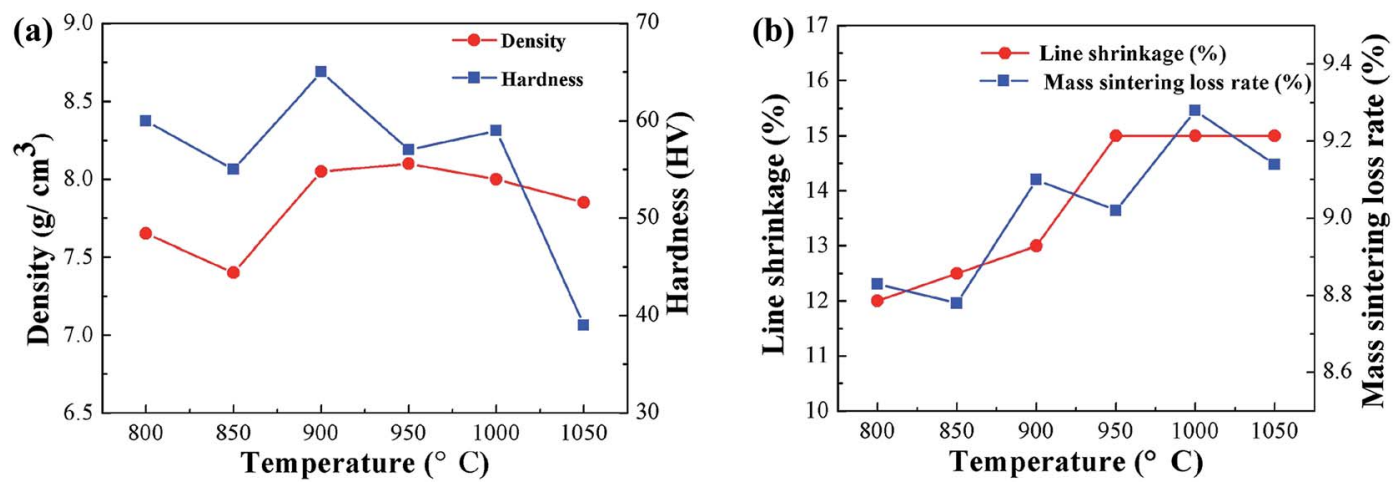

Fig. 8 The effect of the sintering temperature on the physical properties of the sample: (a) the curve of the density and hardness; (b) the curve of the mass sintering loss rate and line shrinkage. 
evolution of the microstructure observed by SEM. Because the probability of the copper atoms obtaining enough energy to cross the barrier to diffuse increases with the temperature increasing, the growth of a sintered neck between the microstructures is promoted. When the temperature reached $1050{ }^{\circ} \mathrm{C}$, the original small separated grains grew into a large crystal, which is an important reason for the decline in hardness. Although, the sintering temperature of $1050{ }^{\circ} \mathrm{C}$ was favorable for the complete growth of the crystal from the SEM image, it is not an appropriate choice. This is because the physical properties of shrinkage, density and other parameters should also be considered. Besides, another heating treatment parameter (holding time) could be selected to further optimize the sintering process.

3.3.2 The effect of holding time. In order to investigate the influence of the holding time on the sintering process, the sintering temperature was set to $950{ }^{\circ} \mathrm{C}$ and the heating rate was $10{ }^{\circ} \mathrm{C} \mathrm{min}{ }^{-1}$. When the holding time increased from $20 \mathrm{~min}$ to $240 \mathrm{~min}$, it was found that the effect of the holding time on the density was not obvious. The density of the sample was basically maintained at about $7.7 \mathrm{~g} \mathrm{~cm}^{-3}$, but the hardness of the sample increased slightly at the beginning and then decreased. It was demonstrated that the hardness reached a maximum of 77.98 $\mathrm{HV}$ at 90 min (Fig. 10a). These results can be confirmed by the microstructure at different holding times (Fig. 11). Too-short holding times led to many pores between the microstructures of the sample, so the hardness was low, as shown in Fig. 11a-c. However, as the holding time increased, the metallurgical bonding between the microstructures was greatly improved, and the internal porosity of the sample gradually became smaller (Fig. 11c-e), so that the mechanical properties of the sample were enhanced. On further increasing the holding time, each part of the microstructure of the sample grew together to form a whole microstructure (Fig. 11e-h) under the combined effect of the surface diffusion, lattice diffusion and grain boundary diffusion mechanisms, ${ }^{19,20}$ while the hardness was reduced. It is displayed in the SEM image that when the holding time was $90 \mathrm{~min}$, the microstructure shows a dense spatial lattice structure (Fig. 11d) so that the sample had superior mechanical properties, which can explain the highest hardness at a holding time of 90 min (Fig. 10a). Fig. 10b shows the curves of volume shrinkage and the mass sintering loss rate under

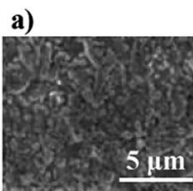

b)
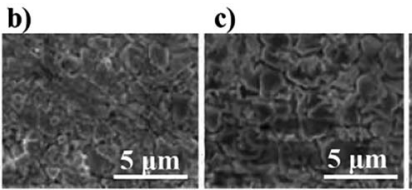

e)

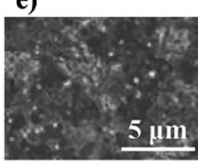

f)

g)
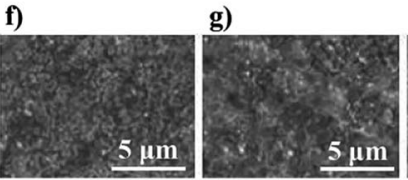

d)

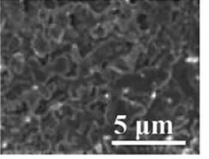

h)

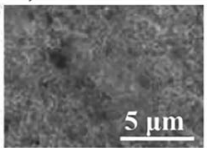

Fig. 11 SEM images of samples at different holding times: (a) $20 \mathrm{~min}$; (b) $40 \mathrm{~min}$; (c) $60 \mathrm{~min}$; (d) $90 \mathrm{~min}$; (e) $120 \mathrm{~min}$; (f) $150 \mathrm{~min}$; (g) $180 \mathrm{~min}$; (h) $240 \mathrm{~min}$

different holding times. It was found that the holding time had little effect on volume shrinkage and the mass sintering loss rate.

3.3.3 Optimization of the heating parameters. The effect of the holding time on the sintering performance can be summarized to optimize the manufacturing process of the components. A sintering temperature of $950{ }^{\circ} \mathrm{C}$ and a holding time of $120 \mathrm{~min}$ are considered as optimal parameters, based on which the metal component sintered from the forming sample (Fig. 6a) had a complex 3D structure, illustrated in Fig. 12a. It was preliminarily found that the component had superior metallurgical bonding, with a flat surface, bright copper metallic luster and a maximum tilt angle of $45^{\circ}$. In order to further evaluate the metallurgical binding effect between the layers (Fig. 12b), the microstructure of the junction between the
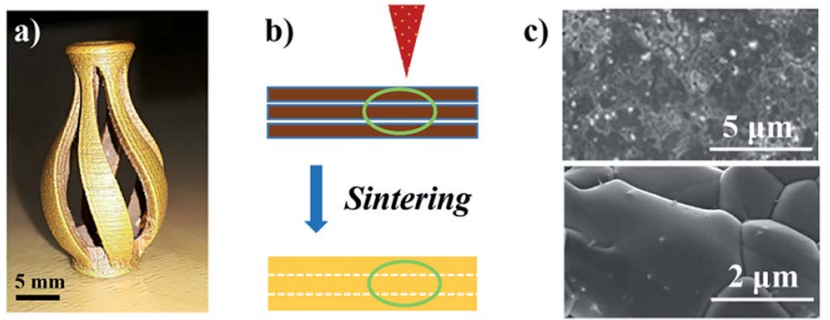

Fig. 12 Analysis of the metal part and its metallurgical bonding: (a) manufactured metal part; (b) junction between the layers; (c) microstructure of the junction.
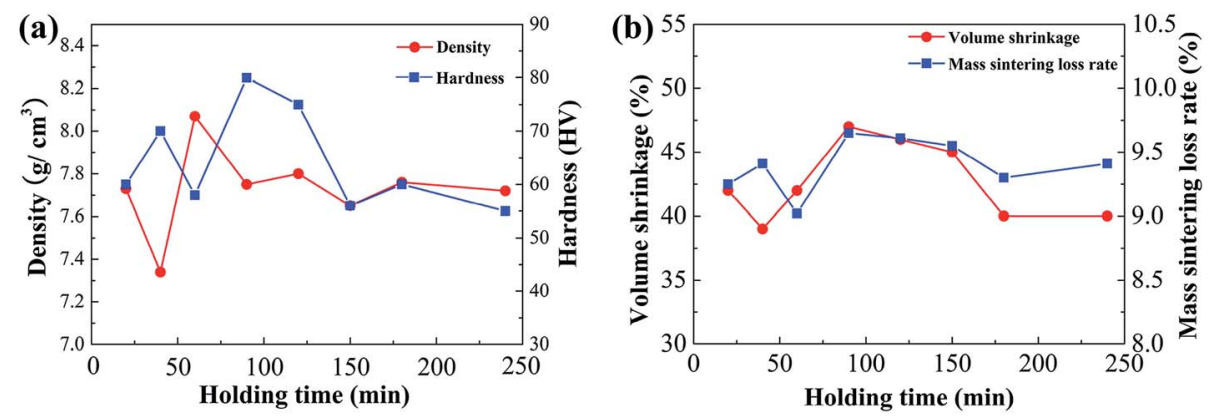

Fig. 10 The effect of different holding times on the physical properties of a sample: (a) the curve of the density and hardness; (b) the curve of the mass sintering loss rate and volume shrinkage. 
layers was observed by SEM (Fig. 12c), indicating that it was metallurgical bonding rather than simple physical combination.

Based on metal paste injection 3D printing, complex 3D metal parts with good performance can be manufactured by optimizing the forming and sintering processes. However, there are more factors that affect the performance. For example, the dewaxing process of this subject is another important fundamental issue. To achieve the manufacture of precision parts, we need to improve the performance of the 3D printer equipment, combined with the optimization of the manufacturing process. Obviously, this study provides a new approach to the rapid manufacturing of complex 3D metals and alloys, which will have great potential in aviation, medicine, jewelry and other fields.

\section{Conclusions}

Copper powder and paraffin wax were utilized to prepare copper paste. Using laboratory-made 3D printing equipment without a mold and based on the MIM, 3D shapes of copper paste with fine surface flatness could be formed under the optimal printing conditions of a drive gear diameter of $7.5 \mathrm{~mm}$, a retraction distance of $1.7 \mathrm{~mm}$ and a layer height of $0.55 \mathrm{~mm}$. The TG-DTA curve indicates that the sintering process of copper paste can be initiated at approximately $300{ }^{\circ} \mathrm{C}$, and the optimal conditions were a sintering temperature of above $950{ }^{\circ} \mathrm{C}$ with a holding time of $120 \mathrm{~min}$. Based on our research, a metal component was manufactured with a complex 3D structure, dense microstructure, superior metallurgical bonding and flat surface. So it can be concluded that metal paste injection 3D printing reveals the feasibility of manufacturing complex 3D metals and alloys by means of a low-cost 3D printing technology without any mold.

\section{Conflicts of interest}

There are no conflicts to declare.

\section{Acknowledgements}

We gratefully acknowledge the financial support by the National Natural Science Foundation of China (Grant No. 51675496 and 51671091), and Wuhan City Applied Basic Research Project, China (No. 2017010201010126). This paper is CJHI contribution CJHIWZ-2017007. The authors acknowledge the financial support of a grant (CJHIXM-S201617) from the Center for Jewelry Heritage and Innovation, Hubei Provincial Key Research Base for Humanity and Social Sciences.

\section{References}

1 M. Vaezi, H. Seitz and S. Yang, A review on 3D micro-additive manufacturing technologies, Int. J. Adv. Manuf. Technol., 2013, 5, 1721-1754.

2 L. I. Li, Q. I. Le-hua, X. U. Lin-feng and Y. Fang, Development of micro-fabrication technology based on material removal, Machinery Design \& Manufacture, 2005, 4, 88-90.
3 W. Michaeli and R. Bielzer, Metal injection molding: Shaping sintered metal parts, Adv. Mater., 1991, 5, 260-262.

4 T. Ebel, V. Friederici, P. Imgrund and T. Hartwig, 19-Metal injection molding of titanium, Titanium Powder Metall., 2015, 337-360.

5 R. M. German, Progress in titanium metal powder injection molding, Materials, 2013, 6, 3641-3662.

6 E. Ergul, H. O. Gulsoy and V. Gunay, Effect of sintering parameters on mechanical properties of injection moulded Ti-6al-4v alloys, Powder Metall., 2009, 52, 65-71.

7 J. H. Martin, B. D. Yahata, J. M. Hundley, J. A. Mayer, T. A. Schaedler and T. M. Pollock, 3D printing of highstrength aluminium alloys, Nature, 2017, 549, 365-369.

8 U. Kalsoom, P. N. Nesterenko and B. Paull, Recent developments in $3 \mathrm{D}$ printable composite materials, $R S C$ Adv., 2016, 6, 60355-60371.

9 L. Hirt, A. Reiser, R. Spolenak and T. Zambelli, Additive Manufacturing of Metal Structures at the Micrometer Scale, Adv. Mater., 2017, 17, 1-30.

10 Y. Mao, Y. Yan, K. Wu, H. Xie and Z. Xiu, Non-equilibrium synthesis and characterization of n-type $\mathrm{Bi}_{2} \mathrm{Te}_{2.7} \mathrm{Se}_{0.3}$ thermoelectric material prepared by rapid laser melting and solidification, RSC Adv., 2017, 7, 21439-21445.

11 O. A. Mohamed, S. H. Masood and J. L. Bhowmik, Experimental investigation of time-dependent mechanical properties of PC-ABS prototypes processed by FDM additive manufacturing process, Mater. Lett., 2017, 193, 58-62.

12 W. Jo, D. H. Kim, J. S. Lee, H. J. Lee and M. W. Moon, 3D printed tactile pattern formation on paper with thermal reflow method, RSC Adv., 2014, 4, 31764-31770.

13 R. M. German, Progress in Titanium Metal Powder Injection Molding, Materials, 2013, 6, 3641-3662.

14 A. Dehghan-Manshadi, M. J. Bermingham, M. S. Dargusch, D. H. StJohn and M. Qian, Metal injection moulding of titanium and titanium alloys: Challenges and recent development, Powder Technol., 2017, 319, 289-301.

15 S. Hwang, E. I. Reyes, K. S. Moon, R. C. Rumpf and N. S. Kim, Thermo-mechanical Characterization of Metal/Polymer Composite Filaments and Printing Parameter Study for Fused Deposition Modeling in the 3D Printing Process, $J$. Electron. Mater., 2015, 44, 771-777.

16 S. Hong, C. Sanchez, H. Du and N. Kiml, Fabrication of 3D Printed Metal Structures by Use of High-Viscosity Cu Paste and a Screw Extruder, J. Electron. Mater., 2015, 44, 836-841.

17 H. Ye, X. Y. Liu and H. Hong, Sintering of 17-4PH stainless steel feedstock for metal injection molding, Mater. Lett., 2008, 19, 3334-3336.

18 R. Supati, N. H. Loh, K. A. Khor and S. B. Tor, Mixing and characterization of feedstock for powder injection molding, Mater. Lett., 2000, 2-3, 109-114.

19 T.-H. Kim, S.-R. Lee, S. J. Yun, S. H. Lim and T.-S. Jang, Anisotropic diffusion mechanism in grain boundary diffusion processed Nd-Fe-B sintered magnet, Acta Mater., 2016, 112, 59-66.

20 R. Mohammadzadeh and M. Mohammadzadeh, Grain boundary and lattice diffusion in nanocrystal $\alpha$-iron: An atomistic simulation study, Phys. A, 2017, 482, 56-64. 